\title{
THE TEMPLATES METHODS IN E-LEARNING OF HIGHER MATHEMATICS
}

\section{Dmytro Bodnenko ${ }^{1}$, Oksana Lytvyn ${ }^{2}$, Sergiy Radchenko ${ }^{3}$, \& Volodymyr Proshkin ${ }^{4}$}

Borys Grinchenko Kyiv University, Bulvarno-Kudriavska St. 18/2, Kyiv, Ukraine 1.bodnenko@kubg.edu.ua, ORCID 0000-0001-9303-6587

${ }^{2}$ o.lytvyn@kubg.edu.ua, ORCID 0000-0002-5118-1003

${ }^{3}$ s.radchenko@kubg.edu.ua, ORCID 0000-0002-6930-5801

${ }^{4}$ v.proshkin@kubg.edu.ua, ORCID 0000-0002-9785-0612

\begin{abstract}
The article considers the peculiarities of the implementation of the templates method in the process of e-learning of higher mathematics for automated generation and visualization of tasks using cloud services. It reveals the essence of the templates method; its advantages as a real and accessible method of automating the creation and use of packages of practical mathematical tasks, and also their visualization. A survey conducted among students sproved the convenience and efficiency of using the method of templates in the process of teaching higher mathematics. The authors discuss features and methodological aspects of the implementation of the templates method using Google Sheet and Overleaf cloud services in the process of e-learning of higher mathematics. The authors present the algorithm of the organization of e-learning of students with use of templates consisting of two stages and highlight the advantages of cloud services in the implementation of the template method in the process of teaching higher mathematics. They include an operational reflection, a comparative analysis of work performed, etc.
\end{abstract}

Keywords: template method; educational process; e-learning; higher mathematics; cloud services.

\section{INTRODUCTION}

Intensification of the university learning process, diversification of its forms (including e-learning, blended learning), an easy and fast access to information resources bring about a number of important problems. They include the development of quality methodological and didactic materials for students (tasks for independent and control works, tests, visual aids, etc.). This problem is especially relevant in the context of e-learning, which involves the necessity to radically change the ap- 
proach to the organization of the educational process in higher education institutions, and obviously requires much more time and effort from teachers and students. Therefore, it is important that tasks solve various aspects of this problem through the following: automatic generation of mathematical tasks to ensure multivariance in the learning process; design of mathematical task texts for students' good visual perception; saving teachers' time in developing the content of tasks; optimization of students' time and effort in the process of solving mathematical tasks; organization of independent work of students in the presence of a significant number of already solved mathematical tasks in free access on the Internet; organization of interaction of teachers and students by means of cloud-oriented learning technologies, etc. Undoubtedly, the selected aspects are relevant for all university disciplines, but they acquire a special significance in the process of teaching higher mathematics.

\section{ANALYSIS OF CURRENT RESEARCH}

According to the results of research, automation of the process of creating and solving mathematical problems allows you to effectively organize both classroom, including remote and independent work of students, reduces unproductive time and effort of students.

Various aspects of the use of automatic generation methods for the development of mathematical methodological and didactic materials have been the subject of research by a number of scientists (Gangur, 2011), (Singh, 2012), (Siu Cheung Hui, 2013), (Nguyen, 2012), (Bodnenko, 2015), (Semenikhina, 2020), (Vollrath, 2015). Thus, V. Byzov (Byzov, 2018) developed an approach to generating tests using a document template in the computer typesetting system LaTeX. The author notes that LaTeX allows you to create documents that contain mathematical formulas of any complexity, edit TeX-files with an external program or script, and correctly convert the source code of the document into a PDF file, regardless of the version of LaTeX. Y. Konovalov and S. Soboliev (Konovalov, 2016) considered different approaches to the construction of automatic generation of control tasks in mathematics, outlined their advantages and disadvantages. We want to note that there are some interesting examples of algorithms for generating problems from some sections of linear algebra and mathematical analysis (Singh, 2012), (Abe, 2013).

In his works, S. Radchenko (Radchenko, 2018, Radchenko, 2019) considers the main ideas of the so-called templates method for generating tasks are given, the mathematical basis of the used algorithms and methodological bases of its realization. The author proposes and substantiates the main advantages of the template method:

- mass creation of mathematical tasks without the use of special programming systems;

- ensuring individualization and control of classroom and extracurricular work of students;

- visualization of educational information that improves the quality of the educational process.

At the same time, the analysis of scientific works showed that the use of methods and technologies for automatic generation of didactic content in e-learning, in particular, 
involving all the features of cloud services, has not yet been the subject of scientific research.

The aim of this study is to find out the peculiarities of the implementation the templates method in the process of e-learning of higher mathematics for automated generation and visualization of tasks using cloud services. To achieve the goal of the study, the following tasks are formulated: to analyse the methodological aspects of using the templates method as a real and affordable method of creating and using packages of practical mathematical tasks for students; to reveal the possibilities of cloud-based learning technologies for the implementation of the method of templates in the process of learning higher mathematics.

\section{MATERIALS AND METHODS}

To achieve the goal we used a set of appropriate methods: analysis of research to establish the problem of automatic generation for the development of methodological and didactic materials in mathematics, in particular, in the development and use of task packages; synthesis, generalization, systematization for theoretical substantiation of methodical aspects of using the template method in the process of teaching mathematics; empirical: diagnostic (conversation, questionnaire) to establish the importance of using the method of templates in the process of teaching mathematics. The study was conducted on the basis of Borys Grinchenko Kyiv University (Ukraine) during 2020-2021. The experiment involved 29 first-year students majoring in Computer Science, studying the discipline "Higher Mathematics" (15 ECTS credits, including Linear Algebra and Analytical Geometry, Mathematical Analysis, Differential Equations). The study took place in four stages: the first stage, theoretical, aimed at clarifying the theoretical foundations of the study. The second stage, practical, involved the creation of packages of practical tasks in the process of studying the topic "Gaussian method for solving systems of linear algebraic equations" using the templates method and its implementation using cloud services, as well as preparing methodological support for this process. At the third stage, the templates method was introduced into the practice of university teaching of higher mathematics. At the fourth stage, the attitude of students to the effectiveness of the templates method in the process of teaching higher mathematics was studied. The research was performed within the framework of a complex scientific topic of the Department of Computer Science and Mathematics of Borys Grinchenko Kyiv University "Mathematical methods and digital technologies in education, science, technology", DR № 0121U111924.

\section{MAIN RESULTS}

The essence of the template method is to create a special environment for the formation of an array of similar tasks and transfer them to an easy to read and perceive electronic format (e.g., PDF). The idea of the method is to combine the capabilities of any spread sheet editor and text editor TeX. 
To find out the importance of using the template method in the training process, we conducted a student survey. Thus, $79.3 \%$ of students believe that it is more convenient for them to receive tasks that are well visualized, has typographic quality. The vast majority of students (75.9\%) support the idea of unifying the presentation of mathematical formulas and sets of symbols. Interestingly, almost all students (96.6\%) say that it is more convenient for them to use an automated system that reduces actions to thinking about the solution algorithm. In fact, in our mobile and fleeting times, it is no longer interesting for students to fill the answers in the context of solving exercises in standard phrases repeatedly (manually). As a positive result of using the templates method in teaching, we consider the fact that $65.5 \%$ of students say that they noticed a difference in learning outcomes after using the templates method. $79.3 \%$ of respondents believe that the template method is convenient, and $69.0 \%$ think that it is flexible.

At the same time, about half of students $(44.8 \%)$ are hesitant about the benefits of receiving individual tasks that are unique to each student. We attribute this uncertainty to the fact that not all students are conscientious and uphold the principles of academic integrity.

In favour of the use of the templates method during the development of students' practical skills show the results of certain mathematical exercises (solving systems of equations by Gaussian method and multiplication of matrices). Thus, there are $15-17 \%$ of errors in the tasks of students who did not use the templates method and $3-7 \%$ of errors in the students' tasks using the templates method.

It is worth noting a number of problems that are successfully solved in the study of higher mathematics using the templates method as a real and affordable method of automation as the creation and use of packages of practical mathematical tasks and their solution by students in the learning process.

1. Any system of exercises will be effective if they are maximally individualized. All students have different levels of mathematical training, which significantly affect their understanding of the material, the scope and correctness of the tasks. The template method provides variation of the content of tasks according to the level of the student. In addition, to develop skills of, for example, solving systems of linear equations by different methods, it is enough not to leave the ring of integers, which simplifies the computational component of the process of mastering the method, increasing the content, which is actually the purpose of learning.

2. Due to the rapid development of digital technologies, the problem of control of students' knowledge is complicated by the fact that many didactic tools (tasks, tests, etc.) with solutions are freely available on the Internet. Students can receive up-to-date information from various sources and share it. Sometimes solving their mathematical problems turns into finding ready-made solutions on the Internet. The templates method allows not only to create any number of exercises with different parameters, but also to quickly change packages of already formed tasks. This reduces the ability of students to use ready-made results, which improves the quality of learning control. 
3. An important requirement for the effective organization of the educational process is to save teachers' time when working with methodological and didactic materials. The template method allows you to develop learning materials in individual sections and quickly make changes without compromising the context and form with minimal time and effort.

4. The availability of the templates method is due to the fact that it does not require of teachers special knowledge in programming, is open and understandable to a person who has a sufficient amount of widespread software.

Methodological materials, especially practical, should be as accessible as possible for students. Individual blocks of exercises, collected from different sources, can differ significantly in several respects: fonts and their notation, a set of symbols for the formulation of similar tasks, text support, and so on. As practice shows, students feel discomfort associated with unusually presented material due to the ambiguity of its perception. The templates method allows students to submit educational material in accordance with a carefully selected format that takes into account the peculiarities of students' visual perception of educational information.

The main methodological aspects of using the template method will be considered on the example of creating packages of practical tasks in the process of studying the topic "Gaussian method for solving systems of linear algebraic equations", in particular, systems of four equations with four unknowns. We present the problem from two sides: the formation and presentation of mathematical exercises in a convenient format with the help of a spread sheet editor, as well as ensuring the process of solving tasks in a cloud environment.

Students are given a joint task to solve a system of linear algebraic equations (SLAE). The solution can be implemented in a cloud environment in the classroom or distance learning process. Each student has the opportunity at any time to choose their own way of solving the task. This solution of the task will be automatically executed in the cloud environment of TeX format editor, followed by the presentation for teacher and students. In order to turn all students performing the tasks, may present the results of their own work.

The use of integers (column of free terms, coefficients before unknowns and solutions) is mandatory, as it frees students from the optional complications of arithmetic and makes the process of solving more obvious. For the first step of mastering the method, such a restriction is quite justified. Note that in this process, classroom work is not the main thing, because students can perform actions remotely synchronously without losing the effect of communication.

\section{GENERALIZED MODEL OF EXERCISE FORMATION:}

a. Using the prepared templates in the table editor, the required number of numeric arrays in the form of rectangular tables is created.

b. A document is created using the TeX text editor, which provides the final look of the tasks.

c. The final form of the document with the list of tasks in PDF format is sent to students for processing. 
d. Simultaneously with the implementation of paragraph b, a copy of the same set of tasks for the teacher is formed with the answers that are laid down in paragraph a.

The whole process of forming a new set of tasks is quite fast. It lasts one minute and can be used during classes with students.

\section{Let's show the algorithm of application of a method of templates with use of cloud} services (web-based spread sheet program Google Sheets and the collaborative cloudbased LaTeX editor - Overleaf [overleaf.com]):

Step 1. Preparation of a file with templates.

1. An online Google Sheet document is created with worksheets for each student, as well as a summary table (a separate Google Sheet worksheet) for the teacher. The document for students forms templates according to the algorithm for solving a specific problem, in our example - solving SLAE. Important: the materials of each participant in the joint work are protected by appropriate access.

2. Student cells are unified by addresses within the document.

3. One cell is allocated on each student sheet for the result of the student's work in text format with TeX codes.

4. Links are created to the same type of student cell addresses with the designations of their names on the teacher's sheet.

Stage 2. Working with the template.

5. With simple actions with standard formulas, students synchronously perform the transformation of their tables (i.e. perform tasks in a single document in Google Sheet, each student on a separate sheet), corresponding to individual systems of equations. In the comments, they indicate only the indexes of the rows of the tables, and the formation of the text of solving tasks is automatic. A fragment of the Google Sheet document after step 5 is shown in Figure 1.

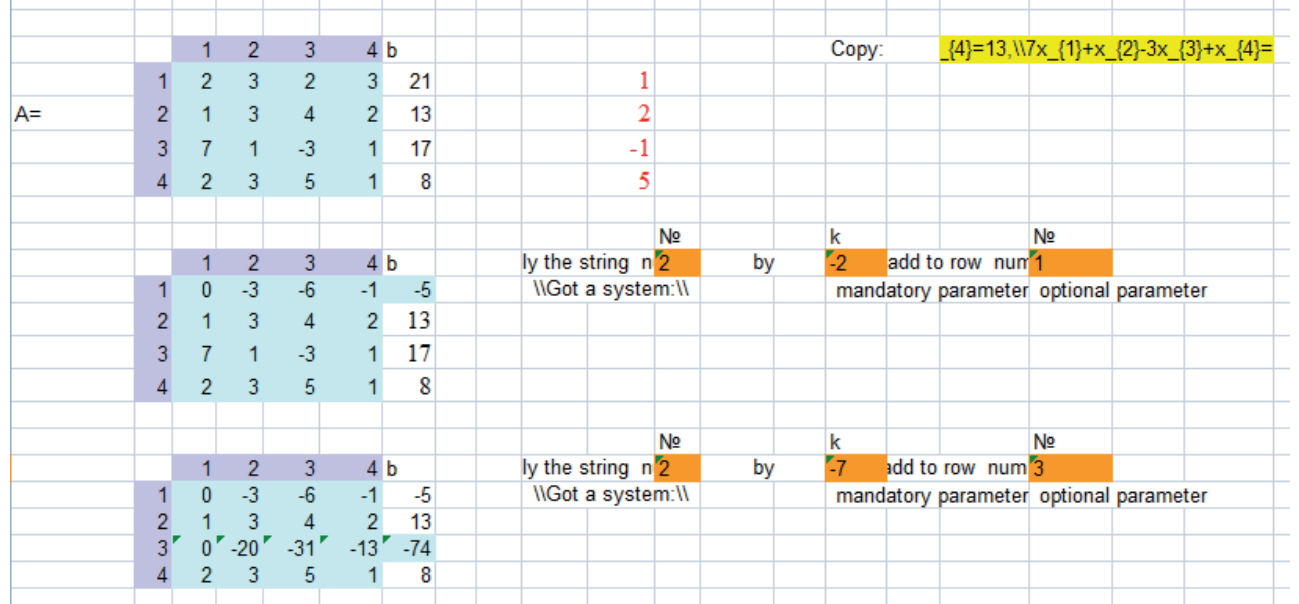

F ig u r e 1. A snippet of the desktop in Google Sheet

Source: Own work. 
6. Then the procedure of pasting all the answers with the names of students, the result of which is placed in the teacher's sheet is done (Figure 2).

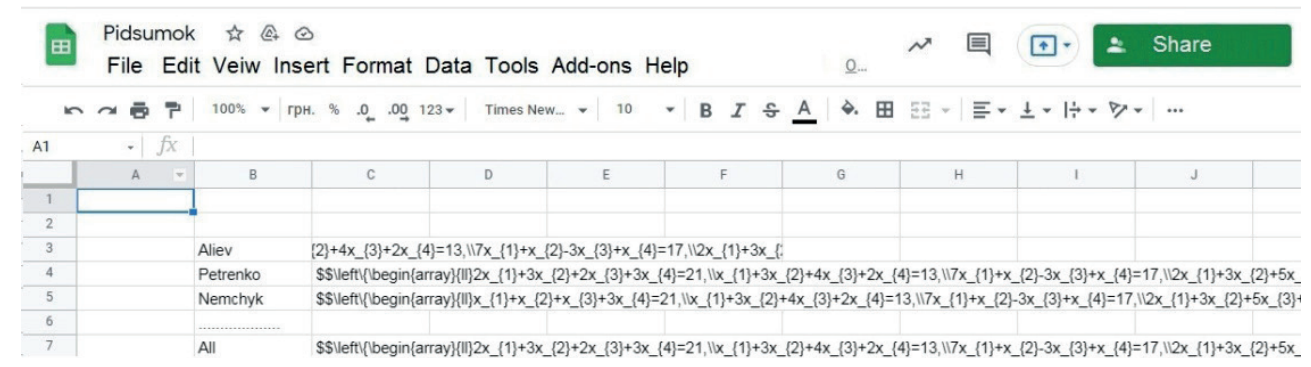

Fig u re 2. A f ile with all answers with the names of students

S ou r e: Own work.

7. The student also sends the completed task to the teacher in the form of a PDF file formatted in the cloud-based TeX editor. The quality of the result after the conversion will be typographic, which has a decisive advantage over the text written by the student himself. Note that students and the teacher with students can share the results of work not only in a PDF file. These can be TeX files that can be edited in any text editor and then converted to PDF without compromising the overall quality of the document.

8. On the teaching sheet of the online file we have a general table of references to all the results of students during the time period defined by the conditions of consideration of the task (in the line "All" we have the final version of the summary solutions).

9. The teacher converts the text from the results sheet into PDF, as a result we have the opportunity to quickly analyse the activities of students and provide a quick reflection on the basis of the obtained data (Figure 3).

In the process of work the question arises - what are the advantages of implementing the template method provided by Google Sheet and Overleaf cloud services? The most important is the operational reflection and comparative analysis of the work performed, which is difficult to do when working with application software installed on a local computer. The use of cloud services also allows:

- the teacher will significantly speed up the process of preparation for the lesson and check the work thanks to the template for joint work in the Google table, and he/she can immediately create a methodological support for independent work of students (for example, a video manual);

- students, in addition to acquiring professional competences, masters the components of digital competence, identified, for example in [Bell]: Cultural (how to behave), Cognitive (how to do), Constructive (how to use), Communicative (how to communicate) Confident (how to belong), Creative (how to make), Critical (how to evaluate), Civic (how to participate).

Therefore, the Google Sheet cloud service in the context of our study is used to create a common resource for synchronous activities (learning and self-learning) and 
interaction (reflection, analysis of work performed). It should be noted that any program (service) that provides such a functionality (useful in this aspect are the functions IMPORTRANGE, VLOOKUP, MATCH, INDEX), can be used to implement the templates method. The lack of programming makes this method accessible and mobile, as a large number of Internet services and software for different platforms allow the use of this method for different devices. In addition for many desktop or laptop, you can use the templates method on other devices (tablet, smartphone, etc.). The previous considerations concerned mainly exercises with numerical quantities. But mathematics operates in many cases with symbolic variables and spatial images (for example, in Problems in the Theory of Algorithms, Data Mining, Group Theory, etc.). What can the template method offer for such material? You can also use a spread sheet to operate on cell indexes. For example, you need to construct an arbitrary "word" by composing it from the characters that are located in the cells of a particular continuous column. Using an arbitrary sequence of indexes, you can randomly mix these cells in the process of pasting their contents.

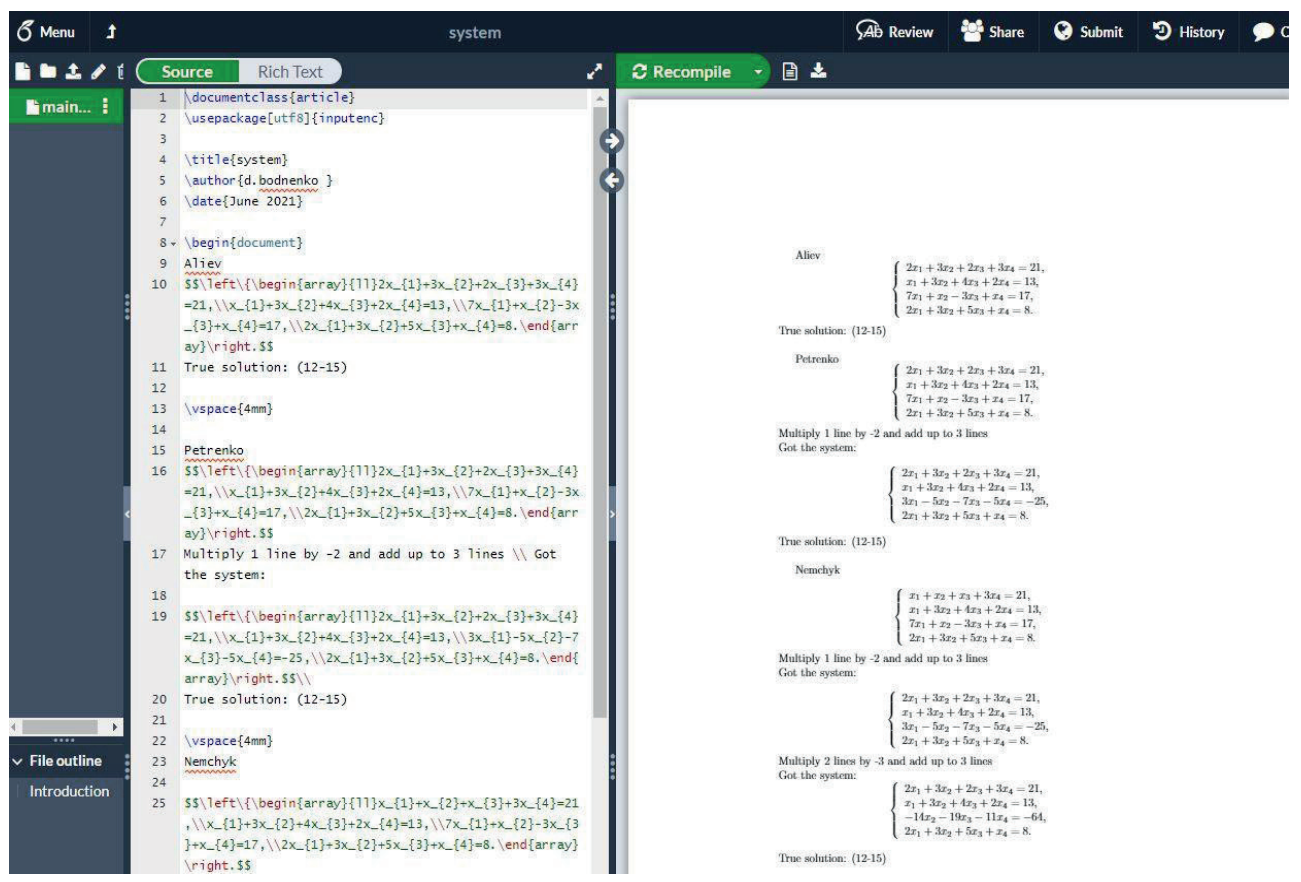

Fig u r e 3. A snippet of the final view of a student-generated PDF solution automatically generated by the cloud-based Overleaf editor

S ou r e: Own work. 
Here is an example. Let the set $\mathrm{K}=\{\mathrm{e}, \mathrm{a}, \mathrm{b}, \mathrm{c}\}$ with an algebraic operation given by the Kelly table:

\begin{tabular}{|c|c|c|c|c|}
\hline$\cdot$ & e & a & b & c \\
\hline e & e & a & b & c \\
\hline a & a & e & c & b \\
\hline b & b & c & e & a \\
\hline c & c & b & a & e \\
\hline
\end{tabular}

Show that the group is Abelian but not cyclic. Find the orders of all its elements. Using the template method, the Kelly table is formed randomly depending on the predetermined result. All possible variants of the Kelly table are considered. In the class, students can choose any version of the table for joint or individual solution with the opportunity to quickly check the results. In addition, using the templates method, it is possible to expand the list of questions for students in this task.

It is worth noting that the template method can also be useful for demonstrating illustrative examples during lectures. The peculiarity of the illustrative material provided by the lecturer is the need to achieve the main goal in a limited period of time, avoiding many details that arise when solving more complex tasks in practice. Demonstrating several exercises solved in one method allows the student to choose the most convenient option for understanding the theoretical material.

There can also be consolidated educational materials in Google Classroom, create LMS resources and integrate specialized services (SCM), involve in diagnostics (Google forms) and promotion (social services), etc.

\section{CONCLUSION}

The essence of the presented template method consists in creating a special electronic environment for forming an array of similar tasks and transferring them to an easy to read and perceive electronic format (for example, PDF). The idea of the method is to combine the capabilities of any spread sheet editor and TeX text editor. The advantages of the templates method as a real and accessible method of automating the creation and use of packages of practical mathematical tasks, and their solution by students include: variation of the content of tasks according to the level of mathematical student training; the quality of control of students' knowledge by providing them with unique tasks, the solutions of which are not freely available on the Internet; minimum time spent by teachers to create methodological and didactic materials without the use of programming, etc. The convenience and efficiency of using the templates method in the process of teaching higher mathematics was confirmed as a result of a student survey. The methodological aspects of using templates as a real and accessible method of creating and using packages of practical mathematical problems for students are analysed on the concrete example.

This study reveals some peculiarities of the implementation of the template method for automated generation and visualization of tasks with the use of cloud services in the process of e-learning of higher mathematics. In particular, it presents an 
algorithm for organizing learning using the environment of templates and Google Sheet and Overleaf cloud services, which consists of two stages. Finally, it highlights the advantages of cloud services for the implementation of the template method in the process of teaching higher mathematics: operative reflection and comparative analysis of the performed works, etc.

\section{REFERENCES}

A b e, K., C orte z, R., \& Va zhen in, A. (2013). Task management strategies for automatic task generation and verification. International Joint Conference On Awareness Science And Technology \& Ubi-Media Computing (Icast 2013 \& UMEDIA 2013). https://doi.org/ 10.1109/icawst.2013.6765510.

B el s h a w, D. (2014). The essential elements of digital literacies. Retrieved from https://dougbelshaw.com/doug-belshaw-edd-thesis-final.pdf (accessed 1 June 2021).

B o d n e n k o, D., R a d ch en ko, S., \& J u r t in, I. (2015). The Usage of Illustration for Material Perception Improvement in Studying Natural Disciplines. SOCIETY, INTEGRATION, EDUCATION. Proceedings Of The International Scientific Conference, 1, 356. https://doi. org/10.17770/sie2014vol1.776.

B y z o v, V. (2018). O opyite ispolzovaniya PYTHON i LATEX dlya avtomaticheskoy generatsii kontrolnyih rabot po matematike [About the experience of using PYTHON and LATEX for automatic generation of test papers in mathematics]. Nauchnyiy Vzglyad V Buduschee. [Scientific Outlook to the Future] (19-01), 39-43. https://doi.org/10.30888/2415-7538.2020 -19-01-011.

G a n g u r, M. (2011, July). Automatic generation of mathematic tasks. In Proceedings of the 7th WSEAS/IASME International Conference on Educational Technologies (EDUTE'11) (pp. 129-134).

Konovalov, Ya.Yu. \& Sobolev, S.K. (2016). Metodicheskie aspektyi kompyuternogo generirovaniya zadaniy po matematike. [Methodological aspects of computer generation of tasks in mathematics]. Mashinostroenie i kompyuternyie tehnologii. [Mechanical Engineering and Computer Technologies] (7). Retrieved from https://cyberleninka.ru/ article/n/metodicheskie-aspekty-kompyuternogo-generirovaniya-zadaniy-po-matematike (accessed 11 June 2021).

Ng u y en, M.L., H u i, S.C., \& Fo n g, A.C. (2012, September). Web-based mathematics testing with automatic assessment. In Pacific Rim International Conference on Artificial Intelligence (pp. 347-358). Springer, Berlin, Heidelberg. https://doi.org/10.1007/978-3-642 -32695-0_32.

R a d ch en ko, S. (2018). Pobudova za metodom shabloniv kompiuteryzovanoho seredovyshcha dlia vyvchennia system liniinykh alhebraichnykh rivnian. [Construction using a computerized environment method for studying systems of linear algebraic equations]. Naukovyi Chasopys NPU Imeni M.P. Drahomanova. Seriia 2. Kompiuterno-Oriientovani Systemy Navchannia [Scientific Journal of NPU named after. Series 2. Computer-Oriented Learning Systems], 20(27), 107-113. https://doi.org/10.31392/npu-nc.series2.2018. 20(27).18.

$\mathrm{R}$ a d ch en k o, S. (2019). Formuvannia za metodom shabloniv skhem heneruvannia zavdan dlia vyvchennia dyskretnykh vypadkovykh velychyn. [Formation by the method of tem- 
plates of schemes of generation of tasks for studying of discrete random variables]. Naukovyi Chasopys NPU Imeni M.P. Drahomanova. Seriia 2. Kompiuterno-Oriientovani Systemy Navchannia [Scientific Journal of NPU named after. Series 2. Computer-Oriented Learning Systems], 21(28), 117-121. https://doi.org/10.31392/npu-nc.series2.2019.21(28).19.

Siu Cheung Hui, Nguyen, M., \& Fong, A. (2013). Large-Scale Multiobjective Static Test Generation for Web-Based Testing with Integer Programming. IEEE Transactions On Learning Technologies, 6(1), 46-59. https://doi.org/10.1109/tlt.2012.22.

Semenikh ina, O., Kud rina, O., Koriakin, O., Ponom a renko, L., Kor inna, H., \& Krasilov, A. (2020). The Formation of Skills to Visualize by the Tools of Computer Visualization. TEM Journal, 1704-1710. https://doi.org/10.18421/tem94-51.

Sing h, R., Gu lwa n i, S., \& R a ja m a n i, S. (2012, July). Automatically generating algebra problems. In Proceedings of the AAAI Conference on Artificial Intelligence (Vol. 26, No. 1).

Voll r at h, J. (2015, March). An open access minimum automatic task generation live feedback system for electrical engineering. In 2015 IEEE Global Engineering Education Conference (EDUCON) (pp. 494-498). https://doi.org/10.1109/educon.2015.7096015. 